\title{
Logistics services and Lean Six Sigma implementation: a case study
}

\begin{abstract}
Purpose: This paper analyses the application of Lean Six Sigma framework for supporting continuous improvement in logistics services. Both the lean philosophy and the Six Sigma methodology have become two of the most important initiatives for continuous improvement in organizations. The combination of both alternatives - Lean Six Sigma (LSS) - brings significant benefits for companies applying this method and its influence in logistics services can be relevant.
\end{abstract}

Design/methodology/approach: A case study on the logistics services of a large consumer electronics company is performed. In this sector, high quality in logistics services is crucial. Using within-case and cross-case analyses, the paper discusses the implementation of LSS in two internal logistics processes.

Findings: The paper identifies important implementation aspects when applying LSS to logistics services, such as continuous improvement structure, strategic analysis, crossfunctional teams, and process management. Furthermore, the paper discusses the potential in logistics services of the DMAIC approach and tools like VSM, SIPOC and Process Mapping.

Practical implications: The paper analyses two logistics processes where LSS has been applied - a payment process and a request-to-ship process. The analysis of both processes offers relevant information about organizational implementation in a logistics services environment, about process improvement and about the use of LSS tools.

Originality/value: Firstly, this paper addresses the gap in literature about LSS and logistics' activities. Furthermore, the case company, with more than 9.000 employees and distributing its products to more than 100 countries, constitutes a valuable source of information to obtain insights in the implications of implementing LSS in logistics services.

Keywords 
Lean Six Sigma, continuous improvement, logistics service, case study, supply chain Acknowledgements

\section{Introduction}

In recent years, the business world has combined the Lean philosophy and Six Sigma to create a new method called Lean Six Sigma (LSS) (Psychogios and Tsironis, 2012; Salah et al., 2010; Salah et al., 2010; Wang and Chen, 2012). This method takes advantage of both philosophies, such as improvement processes from Six Sigma and productivity from the Lean philosophy (Salah et al., 2010; Wang and Chen, 2010, 2012). Because LSS contributes to improving the organizational performance (Snee, 2010), it can represent a key to survival in a global market (Pamfilie et al., 2012).

Despite the interest in LSS, one of the main gaps in current research is that studies so far have failed to consider the organizational context that can influence the relationship between Lean practices and performance (Browing and Health, 2009; Psychogios and Tsironis, 2012). Thus far, studies have mainly observed LSS in specific contexts, such as for example small and medium-sized enterprises (SMEs) (Gnanaraj et al., 2012), the construction industry (Van den Bos et al., 2014) or local government (Furterer and Elshennawy, 2005).

An area that has received increasing attention in recent years, from both academics and managers alike, is the area of logistics and supply chain management (Rahman, 2006). Effective and efficient supply chain management plays a fundamental role in obtaining competitive advantage (Rahman, 2006). Improvements in all supply chain stages results in reduced costs, improved resource utilization, and improved system efficiency (Beamon and Ware, 1998). Thus, logistics managers must develop skills in quality tools and apply them frequently, particularly in core functions such as transport, warehousing and inventory control (Rahman, 2006). High-quality logistics services have become key to predicting a firm's success in the marketplace (Chapman et al., 2003).

Lean and Six Sigma have been brought from manufacturing into the services sector. This is driven by the fact that the world economy is largely based on services (Wang and Chen, 2010). However, despite the importance of supply chain management, there 
is no study available in literature to date that investigates LSS implementation in a logistics service environment. The main purpose of this research is to extend the understanding of the LSS methodology by analyzing its actual implementation in a logistics services environment.

For this purpose, a case study on the logistics services of a large consumer electronics company has been performed. The case study approach provides an explanation of linkages among events, and it is preferred when a real world event is examined, aimed at understanding how or why events occur (Voss et al., 2002). A fast evolving industry was selected for the research, as this industry tends to be thought leading in supply chain management (cf. de Leeuw and Fransoo, 2009). Selecting one case for in-depth study allows studying the company in detail. The study took place during a time-period of 6 months in which the implementation of LSS tools was followed in two different projects.

This study contributes to the emerging literature about LSS, creating a general understanding of how LSS could be used in logistics services environment. This is particularly interesting since little has been written about the actual application of LSS in a logistics services environment.

This paper is structured as follows. The next section offers a global perspective on LSS. The third section describes characteristics of the logistics services context. The fourth section describes the research design for the case study. The fifth section explains the main results obtained and discusses them. Last, the paper discusses conclusions, limitations and further research.

\section{Lean Six Sigma and logistics}

\subsection{Lean Six Sigma}

LSS can be defined as a broad long-term strategic decision-making method which maximizes value added content and minimizes variation of quality and process characteristics, thereby improving customer satisfaction. Its objectives are to improve customer satisfaction, increase process speed and reduce costs (Cheng and Chang, 2012). LSS has become a popular continuous improvement (CI) approach (Devane, 
2004; George, 2003; Shah et al., 2008) and many public and private organizations such as BAE Systems Control or Northrop Grumman have implemented it (Furterer and Elshennawy, 2005). Its implementation in these environments has led to numerous benefits, such as increased quality of the products, higher reliability of processes, eliminated rework time, improved productivity or increased system flexibility (Arnheiter and Maleyeff, 2005; Chen et al., 2010).

LSS integrates the Six Sigma methodology and the Lean philosophy. Six Sigma, is original from Motorola and is defined as "an organized, parallel-meso structure to reduce variation in organizational processes by using improvement specialists, a structured method, and performance metrics with the aim of achieving strategic objectives" (Schroeder et al., 2008, p. 540). Six Sigma methodology goes beyond quality assurance or quality control and is close to the concept of total quality management (TQM) (Green, 2006; Gutierrez, et al., 2010). For example, Green (2006) observes how Six Sigma is developed across five main TQM components: customer focus, employee involvement, continuous improvement, leadership and fact-based decision making. Literature agrees about the positive effects of Six Sigma on operational issues, such as project savings, on-time deliveries, and reduction of inventory and setup time (Braunscheidel et al., 2011; Linderman et al., 2006; Sunder, 2014; Sunder and Antony, 2015) and on learning, quality or innovation (Choi et al., 2012; Gutierrez, et al., 2012; Swink and Jacobs, 2012).

The lean philosophy is derived from Toyota Production System (TPS). This philosophy pursues the reduction of lead times, delivery times, uncertainties in quality, inventories, set up times, equipment downtime, scrap, rework and other wastes (Kumar et al. 2006; Arnheiter and Maleyeff, 2005). Consequently, lean implementation is positively related to performance improvements (Eroglu and Hofer, 2011; Shah and Ward, 2007; Shah et al, 2008). However, there is still confusion about its correct implementation and how it works (Shah and Ward, 2007; Staats et al., 2011). Lean philosophy collects ideas from preventive maintenance, pull production, human resource management and quality management; its original tools such as PDCA are fundamental (Furlan et al., 2011; Motwani, 2003; Shah and Ward, 2003). Lean relies on standardized work procedures together with the use of a set of tools and techniques such as Kaizen, 5S, process/value 
stream mapping, Kanban or Poka yoke, to identify and remove the waste from processes (Fullerton et al., 2014; Shah and Ward, 2003, 2007; Vamsi and Sharma, 2014).

Six Sigma and Lean integration brings more benefits than those obtained from implementing each initiative separately (Arnheiter and Maleyeff, 2005; Bhuiyan and Baghel, 2005; Cheng and Chang, 2012; Salah et al., 2010; Snee, 2010). Bhuiyan and Baghel (2005) explain that with the use of both methods, more ways are created in which significant improvements can be made in terms of cost, quality and lead times. Shah et al. (2008) show how Six Sigma moderates the relationship between Lean bundles and manufacturing performance, confirming the interdependence and complementarity between both initiatives. Six Sigma provides a suitable structure for deploying improvement projects that benefits Lean management (Shah et al., 2008). Furthermore, the integration of Lean and Six Sigma increases the autonomy of employees, strengthening the solidity of the CI processes (Pepper and Spedding, 2010). Therefore, integrating Lean and Six Sigma provides high potential for improvements (Arnheiter and Maleyeff, 200; Salah et al., 2010; Snee, 2010); Lean and Six Sigma individually cannot achieve the required improvements at the rate at which LSS can (Bhuiyan and Baghel, 2005).

\subsection{Logistics services}

Services are generally a dominant part of economies. Literature in the domain of logistics and supply chain management has generally been criticized because of a dominant manufacturing focus (Ellram et al., 2004). The term logistics has traditionally been used in business to describe the management of material and information flows (Davis and Manrodt, 1994). According to CSCMP (2015), logistics include services such as transportation, warehousing, inventory management, packaging, and materials handling, order fulfilment, logistics network design, and supply/demand planning, among others. Chapman et al. (2003) defines logistics as an extension of physicaldistribution management, pertaining to the management of the materials and information stream of a business, down through a distribution channel, to the end customers. Service logistics, on the other hand, is a very different concept. It coordinates the interaction between the (individual) customer and the organization (Davis and Manrodt, 1994). Following Davis and Manrodt (1994) logistics in services is 
involved with reducing lead-time between the scheduling, the performance and the evaluation of the procedure.

Logistic services are integrated with purchasing, operations and marketing with the end customer as its prime focus (Fung and Wong, 1998) (see Figure 1). All these activities are closely connected to the product flow in a supply chain.

One important aspect when modeling a supply chain is the way a firm can interact with the customer (Davis and Manrodt, 1994; Sampson and Froehle 2006). A firm can internally plan what it will offer to the customer, where after the customer can accept or reject the offering. A firm can also plan the capacity to respond to individual customer needs as these arise. In this case, the customer interacts with the provider to define what services will be provided (Davis and Manrodt, 1994). It is important to remember that processes involving customer inputs (service processes) are fundamentally and managerially different from non-service processes (Sampson and Froehle, 2006). Moreover, processes involving even slight customer inputs differ dramatically from processes devoid of customer inputs (Sampson and Froehle, 2006).

Logistic services may mean different things to various organizations and emphasis may be placed on different concepts (Heskett 1971). If there is a focus on logistic quality this could mean that organizations develop strategies aiming to make order cycle times shorter and more predictable, as well as maintaining certain levels of in-stock availability and certain fill rates on customer orders (Rahman ,2006). When there is a focus on the service processes, the emphasis must be on timeliness characteristics (e.g. delivery time) and service non-conformity characteristics (such as proportion of customer complaints every month, number of billing errors) (Antony, 2004). Overall, in logistics services human labor is a dominant force. Furthermore, logistics services are often outsourced ( $\mathrm{Lu}$ and $\mathrm{Su}, 2002$ ). The need to take many different aspects and stakeholders involved into account makes precise control difficult (Ellram et al., 2004). These aspects make it important for a shipper to maintain an accurate overview of logistics performance, thus making logistics services an interesting area to apply lean and quality principles.

Insert Figure 1 about here 


\section{Research design}

\section{Case study introduction}

This study focuses at a high-tech consumer electronics company with more than 9.000 employees world-wide, distributing its products to more than 100 countries. The name of the company is not disclosed for confidentiality purposes. A high-tech consumer electronics company is a fast-changing industry (de Leeuw and Fransoo, 2009), and therefore ideal for applying LSS.

The site of investigation is a so-called European Services and Distribution Centre, and is located in the Netherlands. Here, the company plans and monitors all the logistics activities and supporting processes that take place in the EMEA-district (Europe, Middle East and Asia). Some example of these logistics services are: postponement, delivery, control processes, order processing, distribution, and customer services. This site therefore is a logistic services environment. If sales processes would also be part of the site where LSS is applied, objectives can be more sales based instead of based on logistic service quality and the findings would be less valid for drawing conclusions.

At the start of this case study, the site already took the first steps in implementing a Continuous Improvement (CI) methodology. The company had created a CI plan mainly based on LSS tools. On the site some continuous improvement projects (referred to as CIPs), based on this CI plan, had already taken place. The study included CIPs for two processes. One was oriented to financial aspects in the supply chain - the payment process - and the other was oriented to operational aspects - cycle time management. Table 1 gives an overview of the main characteristics of the two selected CIPs for this research.

Insert Table 1 about here

\section{Data collection}


For this research, the senior quality manager of the case company site served as the prime contact. This manager also served as the LSS implementation manager of the site. Therefore, the contact was helpful in identifying the right cases and the right people to interview.

After consultation with the LSS implementation manager, the two CIPs explained above in Table 1 were identified based on the following requirements: they took place within the logistic services environment and LSS was s applied within each CIP. No other CIPs were identified that met these requirements. Each CIP was shortly discussed with the CIP leader in order to investigate the extent of LSS used and its relation with the logistic services environment. The research included two CIPs as cases to cover different aspects of the logistic services environment while in depth research would still be possible.

The research used primary sources as well as secondary sources. Observations were done during CIP meetings. Secondary sources consisted of training materials, CIP documents and organizational control documents used on site. Interviews were held with the implementation manager as well as with team leaders of the two CIPs. The interviews were semi-structured in order to receive all relevant information on the applicability of LSS.

After the interviews, the data were summarized and categorized in a document. This resulted in case narratives. This document was then sent back to the interviewees, who gave feedback on the document in a second appointment in order to increase content validity and accuracy. If needed the document was adjusted, and a third or fourth appointment were made, until there was full agreement on the findings described. This process of seeking convergence and clarification is important during the data collection (Voss et al., 2002).

\section{Data analysis}

Eisenhardt (1989) suggests that there are two steps in data analysis: data analysis within each case and searching for cross-case patterns. By following these steps and methodological guidelines derived from Voss et al. (2002), this study tries to overcome typical limitations of using case studies and to increase the validity of the findings. 
The overall idea of within case analysis is to become intimately familiar with each case as a stand-alone entity, and allow the unique patterns of each case to emerge before generalizing across cases (Eisenhardt, 1989). This research is focusing on the process of LSS implementation and application. One technique suited for this purpose is explanation building. Here, the goal is to analyze the case study data by building an explanation for the case. Thus, the result of the within case analysis is a description of the findings/explanations of each of the cases.

The next step was to analyze the interview documents to elicit employee reactions, facts, and other data that indirectly provide information about the way LSS has been applied. Special attention went to opinions or facts that combine an aspect of LSS with the characteristics of the logistics service environment. Also, the relation of the CIP with the logistic services environment was analyzed and discussed. Furthermore, whether the information derived from observations and desk research was conflicting or in line with the information from the interviewees was investigated. This deliberate seeking of confirmation from multiple data sources leads to more reliable results (Voss et al., 2002). As a result, the research enabled to obtain complete information about each CIP, which is useful to establish relevant propositions.

\section{Cross-case analysis}

After the within case analysis, a cross-case analysis was performed. Here, the findings of the cases are compared to increase the validity of the findings. Therefore, the research included the interview with the implementation manager in the analysis, as well as findings from observations and documents.

The cross-case analysis combines the different relevant data, where general conclusions can be discussed. When the greater part of the cases implies a certain factor as important in a certain phase within the implementation, explanations can be built relatively easily. However, if the case study findings are not that obvious, more analytic insight is demanded of the explanation builder. This study tries to reduce this problem by constantly referring to the purpose of analyzing LSS implementation.

\section{Results and discussion}


A common process based on the framework proposed by De Leeuw et al. (2013) for LSS implementation in logistics services to analyze both projects was followed. To introduce each CIP project, it is necessary to observe its relationship to the logistics services first and then to analyze how it is related to organizational aspects (e.g. top management support, supervision or linkage to business strategy). Then a discussion about process implementation aspects focused on the DMAIC (define, measure, analyze, improve and control) approach and LSS tools employed is included. Both CIPs are described below.

\subsection{Case analysis project 1: CIP payment process}

\subsubsection{Relation with logistics service environment}

The customers of the CIP 'Payment Process' are third parties and the case company itself. There is no direct contact between the 'Payment Process' and the customers of the case company business. However, the activities clearly relate to the physical flows of goods although the process does not have a direct influence on the supply chain. Without the main logistics activities, this process would not exist (no goods flows, no payment process needed). Therefore, this CIP is identified as a supporting activity of the logistics services.

\subsubsection{Perspective on the organizational implementation}

The goal of the Payment Process project was to use several LSS tools in order to improve the process significantly and at the same time to learn from using these tools. However, a clear application guideline for applying LSS to the process was not available. In consultation with the implementation manager, some tools were suggested but the application of these tools was often confusing. During the observations, it became clear that the interviewee often had to search for information on certain tools on the internet or in books. He indicated that, in the future, the company should make more time and resources available for training of tools and CIP initiatives.

The CIP payment process followed the DMAIC approach. During the 'Define/Measurement' phase, the scope of the project had become bigger and more people had been included in the CIP team. This enabled the collection of additional information and the creation of a total view of the process in order to identify potential 
improvements. However, cooperation in the team was difficult to achieve. Management involvement could be helpful to enhance this cooperation.

Furthermore, there were difficulties in defining the key requirements of the process. Therefore, a more complete overview that summarizes the key requirements would be helpful in creating a more efficient CIP.

\subsubsection{Information about the process implementation}

The 'define' and 'measurement' phase of this CIP were done jointly in one go. The CIP was firstly aimed to creating more transparency in the process. Therefore, measurements were needed to complement the process map. From this map, aspects for further analysis could be identified. After a meeting with the site director, the direction for the remainder of this project became clear, and the 'Analyze' phase was started. This management involvement was helpful to continue the project. The 'Improve' and 'Control' phase did not take place in the time span of this case study.

The 'Define/Measurement' phase was helpful in creating a first idea of the project. Although some points of the project charter were difficult to define, like a timeline and deliverables, the result of these phases was that the scope and the deliverables became clearer. A detailed process map was the key to create a complete overview of the process and identify aspects that required more research.

The 'Analyze' phase of this CIP focused on filling the gaps of the process map with the available information. For example, the key requirements for the next entity in the process had not been defined. Eventually, contracts with customers (third parties) provided the basis to derive requirements. A complete process overview would facilitate finding significant improvements. In addition, it was $\mathrm{s}$ indicated during the meetings that the process probably included non-value added processes. For example, if no failure occurs in the process, a 'check' will be an unnecessary activity.

During a CIP meeting, it was recommended by a manager to document the CIP process very thoroughly. The manager noticed that the roadmap of this CIP could be useful for similar processes. Thus, after finishing this CIP, the documentation may be used to improve efficiently similar processes as well.

\subsubsection{Detailed information about LSS tools}


Firstly, it turned out to be complex to define the voice of the customer (VOC) in the CIP (eventually defined as an internal customer). Moreover, the reliability of defining the VOC was questioned: 'A VOC can be helpful, but is not completely reliable. What if the person next in line has no clue of the process goal?' Secondly, a first idea of the project was s created with the project charter; the process map contributed to defining points for further analysis. Thirdly, the SIPOC tool (which stands for Supplier, Input, Process, Output, and Customer), was helpful in the beginning of the CIP to define the scope and categorize the process in chronological way. Also, after using SIPOC it was easier to create a process map. Finally, the Value Stream Mapping (VSM) tool was not used, because the process was not time based.

4.2. Case analysis project 2. CIP Cycle time from request to ship

\subsubsection{Relation with logistics service environment}

The process starts with the release order from the retailers (the customers). The Customer Service department is the main department included in this CIP. The processes within the CIP influence the physical flow of goods and the related information flows. The processes of this CIP can influence many logistic service quality concepts. The CIP mainly has a focus on the concept of timeliness: the goal of this CIP was $\mathrm{s}$ to reduce the average cycle time from order request to the point of shipment.

\subsubsection{Perspective on the organizational implementation}

This CIP was initiated by higher management because the average lead-time of the site did not meet the strategic requirements. Because of the initiation by higher management, the CIP is linked to the business strategy and people in charge received the required management commitment and resources available to guide efficiently this CIP.

The CIP leader took the role of motivator and facilitator. One of the main tasks was to check frequently on the action items of team members, which were derived from CIP meetings. To maintain a steady pace in the process, it was necessary that each member did his or her homework well before each CIP meeting. The other responsibility of the CIP leader was to communicate the progress with higher management. 
Although the CIP leader had received training in LSS tools the people involved in the CIP rather than tools made this project to a success. The tools were helpful, as will be explained below, however, working with employees who were motivated to improve the process was the most important aspect'.

\subsubsection{Information about the process implementation}

The DMAIC approach was not strictly followed, but served as a guidance. The DMAIC approach was mainly used by management to check and control the CIP and its progress. People involved in the CIP found the steps quite logical and no additional guidelines were needed for improving the process. The following steps were defined by higher management, which are in line with the DMAIC approach:

- Define project team, current status and requirements.

- Find the factors with biggest impact by collecting data/ setting up measures.

- Analyze the findings and potential solutions.

- Implement selected actions.

- Control if order cycle improved and potentially implement corrective actions.

Regarding the participants, the team leader involved other process owners from the start. Input from the process owners was necessary in the CIP and therefore it was more effective to include each relevant process owner in the team from the start. The team finally consisted of seven people. One remark at the end of the CIP was that there were too many people in the team and some of them had not added value to the project. As indicated before, it would be most effective to have a small and motivated team, where it is always possible to ask other people for help.

In the 'Define' phase, a clear project plan was created. The team worked with fixed dates for the meetings and with action items after each meeting. This project management style worked well. Documents showed that each meeting had been documented clearly, and the progress of the action items could be followed easily. The documents were available for everyone, and good documentation helped in continuously motivating the team members. 
Defining the process was a valuable step in this CIP. Detailing the complete process allowed to identify what to measure and analyze. It even already entailed in a 'quick win': a small adjustment that was made in the process based on the process definition reduced the cycle time enormously. This indicates that improvements can be made throughout the whole LSS preparation and implementation process - even in the definition phase. The 'Define' phase turned out to be the most important step in the overall process.

The 'Measurement' and 'Analyze' phase were done jointly. To reduce the overall cycle time, the team first had to measure the lead times of each process and analyze these times. This was done by the business analyst who had also worked on the measurements of the Perfect Order Index (POI) ${ }^{1}$. The team needed a member who knew where to collect the required data and how to interpret the measurements. Therefore, the measurement of the POI was helpful.

The basic processes within the CIP were straightforward. It therefore soon became clear that they had to analyze the exceptions, in this case the hold procedures. It was not difficult to find causes of these exceptions, and the team questioned the people involved based on this.

The improvements made in this CIP were eventually based on standardization of the hold procedures and, as result, the average order cycle was improved. Several employees received new responsibilities for controlling these improvements, and extra documentation was made available for each employee within the process. All process owners received a desk version of the hold procedures, and one employee got the task to act as 'hold police' to check if the process owners meet the new procedures. Next to this 'hold police', the CIP leader calculated the overall cycle time monthly and analyzed the differences when they occurred. Because these control measures where just implemented, information on how successful this control plan was not available.

Although the average cycle time was reduced, it was acknowledged that reducing the cycle time does not necessarily lead to a higher customer satisfaction per se. Customer satisfaction depended on a trade-off between providing additional service and adhering to standard service procedures. The customers - who came from different countries -

\footnotetext{
${ }^{1}$ The POI is a measurement system that measures the service level in the organization. Employees can analyze the data to see which part(s) of the process needs improvement. The POI shows what $\%$ of the orders is in time, in full, error free and damage free.
} 
differed a lot; some of them preferred to have a lot of flexibility, while others preferred standard procedures.

\subsubsection{Detailed information about LSS tools}

Visual management tools such as graphs of lead times per country were used to motivate employees and thus were helpful. Furthermore, the most helpful LSS tool was the VSM. With the VSM, information about the lead times of the different processes was obtained and waste was identified. The SIPOC tool was less helpful, because all the processes within the CIP were not very complex and well known up front.

\subsection{Cross-case analysis}

In this section, case analyses, interviews and secondary sources are discussed to obtain an overall perspective of LSS implementation. To facilitate the analysis, following De Leeuw et al. (2013), the study divided into organizational implementation issues and process implementation issues. Organizational implementation issues are discussed below according to eight practices: strategic analysis, cross-functional teams, measurement system, organizational infrastructure, training, process management, top management involvement and supervision. For process implementation, each phase of the DMAIC approach was discussed.

\subsubsection{Organizational implementation}

\section{Strategic Analysis}

Following the CI Master Plan, the objectives for the CIPs were to: 1. Change behavior. 2. Enhance end to end collaboration. 3. Improve on-time delivery, quality and reduce costs. Two of these points are in line with one of the nine logistic service quality concepts (Mentzer et al., 2001). End to end collaboration refers to the efficiency and effectiveness of the procedures followed by the supplier, and therefore can be seen as part of the concept 'Ordering procedures'. Improving on-time delivery clearly refers to the concept of Order Accuracy. Thus, the strategic objectives are (at least partly) based on logistic services quality concepts. The CIP 'Order Cycle' objective was directly imposed by higher management as a strategic imperative. It is interesting to mention that the implementation manager explained that particularly this CIP had an impact on 
business performance. This suggests that linking the improvement projects to business strategy is critical to applying LSS successfully.

\section{Cross functional teams}

The implementation manager explained that after the CI introduction a bottom-up approach was initiated. However, the CIP 'Payment process' had significant difficulties with cross-functionality of teams. This CIP indicated that management involvement was needed to involve other parties in the CIP and thus to implement cross-functional teams.

\section{Measurement system}

The case company initiated a Perfect Order Index 'POI' to create a new system for measuring service levels. The implementation manager as well as the team leader of the 'POI' explained that a new measurement system, which includes all relevant aspects of the service perceived by the customer, was needed to create insight for improvements.

The 'Order Cycle Time' clearly indicated that the measurements from the POI were valuable for the progress and results of its CIP. Including a business analyst in the CIP teams resulted in helpful information and data being derived. Nevertheless, the CIP 'Payment Process' did not benefit from this new measurement system. The POI measured the percentage of orders on time, in full, error free and damage free. The CIP 'Payment Process' did not have a direct relation with the process affecting this metric.

The POI in the case company first had a focus on an average customer, though it was also possible to relate the POI to customer specific requirements. This study therefore considers the POI as a suitable measurement system for many logistic services CIPs.

\section{Organizational infrastructure}

The implementation manager explained that, from the start, control documents were in place to check the progress of the CIPs. To be able to control all the initiatives, the quality department created a 'CIP project indicator overview'. The CIPs had to indicate their timeline and deliverables, amongst others, in this document. In addition, the quality department provided a weekly update about the progress of the CIPs in a management meeting. With these updates and with the updates from their employees, managers could follow and control the CIPs of their department. This was helpful in keeping control over the CIPs. 
The budget for all the implementations should also be in place. The 'Payment Process' case made clear that there should be sufficient time and resources available for CIP initiatives. Consequently, having the appropriate organizational infrastructure should be in place in order to reach a successful process application.

\section{Training}

The case site had decided to follow the DMAIC approach since the same approach was successfully applied in the manufacturing environment of the case company. Both CIPs found the guidance of the DMAIC approach helpful. However, little practical experience on LSS tools was available within the site. In order to keep a steady pace in the organizational implementation, a 'trial and error' strategy was used. By applying different LSS tools to CIPs and documenting the results of these tools, the goal was to create a blueprint for the applicability of the LSS tools in their processes. This implied that training material needed to be revised based on insights derived over time in order to make new CIPs more successful. Furthermore, there is a need for appropriate training materials available upfront. Furthermore, both cases showed examples of tools that turned out to be not so helpful in the progress of the CIP.

\section{Process management}

For the CIP 'Payment Process, the 'Define' phase pointed out that the scope of its CIP needed to be increased. As a result, this CIP had to involve other parties outside the CIP team and concluded that a high level overview is needed to improve efficiently a small part of the process. This stresses the point of creating a high-level process map.

The CIP 'Order Cycle Time', on the other hand, started with a wider scope, and later, during the 'Analyze' phase, zoomed in on details. The team leaders explained that this CIP continuously measures the overall cycle time or service level as a guide for continuous improvement. The case study findings thus stress the point of performing high level process mapping.

\section{Top Management involvement}

The team leader of the CIP 'Payment Process' explained that when this CIP increased its scope, management involvement was needed to continue the CIP because of the need to involve others. The team leader of the 'Order Cycle Time' explained that because of 
the fact that its process was high level, management involvement was already guaranteed. This team also consisted of several managers. When higher management initiates a CIP, they will follow the progress of the CIP more closely and their involvement is thus guaranteed. The case study findings indicate that high level processes need management involvement anyway, whether it is to coordinate the CIP or control its performance.

\section{Supervision}

Both CIPs indicated that there was enough management commitment and involvement within the ESDC (European Services and Distribution Centre). The control documents were in place and the interviewees acknowledged that the quality department put a lot of effort in creating a CI culture. However, the management commitment/involvement did not go beyond the ESDC managers, as the CIP 'Order Cycle Time' indicated. The implementation manager also explained that more commitment/involvement by global (supply chain) managers would have increased the benefits of the CIPs. It seems therefore more important that companywide resources are available instead of using improvement supervisors.

\subsubsection{Process implementation}

Both CIPs argued that having a structure in the CIPs is helpful. However, many interviewees argued that with logical thinking they would have followed the same general steps as the DMAIC approach prescribes. Moreover, most CIPs indicated that they combined phases of the DMAIC approach for different reasons. Both CIPs even showed that some 'quick' improvements can also be made in the beginning of the CIP, instead of only during the 'Improvement phase'. None of the CIPs indicated that these flexible approaches to using the DMAIC structure would have reduced the performance of the CIP. Although it remains unknown what the results of the CIPs would be if the DMAIC approach was strictly followed, this study concludes that the DMAIC approach provides a good structure. DMAIC does not have to be strictly followed in logistics services to have successful CIPs.

\section{Define phase}

The 'Define' phase was, together with the 'Measurement' phase, the most important phase of the project. The 'Payment Process' showed that this phase resulted in a well- 
delineated scope and deliverables. The 'Order Cycle time' CIP indicated that defining the process was the most valuable step in this CIP. Defining the process also entailed in identification of a quick improvement in at least one CIP. These findings therefore indicate that the first steps of the improvement process implementation are important.

- $\quad$ Voice of the Customer (VOC)

The CIP Payment Process' indicated that it took considerable effort to define critical customer requirements. The CIP 'Order Cycle Time' defined its main requirement as reducing the cycle time from the request of an order until the point of shipment. This refers to the time between order placement and receipt and therefore it is defined in line with 'Timeliness', one of the nine logistics quality concepts of Mentzer et al. (2001). The CIP 'Payment Check' did not define any of its requirements in line with these nine quality concepts. As indicated before, this is probably because this process does not have a direct influence on the total supply chain.

\section{- Supplier, Input, Process, Output, Customer (SIPOC)}

SIPOC identifies all relevant elements of an improvement project. In the 'Payment Process' CIP, the SIPOC tool was helpful in defining the scope and in categorizing the processes in a chronological way. SIPOC facilitated the creation of a process map well.

However, the 'Order Cycle' CIP indicated that the SIPOC was less helpful to them because all the processes within this CIP were known upfront. When the relevant elements are known up front, like in the case of the CIP 'Order Cycle', the SIPOC tool is not needed.

\section{Measurement phase}

\section{- $\quad$ Value Streaming Mapping (VSM)}

The CIP 'Order Cycle Time' identified that VSM was relatively easy to apply because this process was time based. This statement is confirmed by the CIP 'Payment Process' that indicated that VSM was not useful because their process was not time based. Consequently, the type of process analyzed determines the usefulness of VSM.

\section{- Process Mapping}


A complete process map is helpful in identifying significant improvements, according to the CIP 'Payment Process'. The CIP 'Order Cycle Time' did not make a detailed process map and showed that without a detailed process map the cycle time could be reduced enormously as well. VSM seems helpful when the investigated processes consist of several processes and process mapping is helpful when the investigated processes have a small scope.

\section{Analyze phase}

During the Analyze phase, the CIPs were all searching for the causes of problems identified during previous stages. The CIPs did not use any LSS tools during these final phases. The CIPs mainly analyzed issues derived from prior steps by following the process flow and asking employees involved for an explanation.

\section{Improve phase}

Only the CIP 'Order Cycle' went through a complete 'Improvement' phase. This CIP resulted in an improvement to eliminate the root cause, which contributed to the decrease of the flow time. However, one can argue that the other CIP "Payment Process" is also aimed at reduction of flow time. The CIP 'Payment Process' had indicated that the process includes non-value added processes. When removing these processes the total time spent - and thus the process 'flow time' - could be reduced enormously. However, the original objective of this CIP was not to reduce the flow time. Therefore, the case study findings indicate that the improvements in this CIP have their influence on the flow time, but are not necessarily developed for reducing the flow time.

\section{Control phase}

The only control plan made was the one from the CIP 'Order Cycle'. The hold procedures were standardized, documented, and all process owners received a desk version. Because these control measures were implemented relatively recently, there were no further comments on how successful this plan was.

\section{Conclusions}

Through case-study research, this paper shows how LSS may contribute to improving the performance in a logistics services environment. The logistic services environment 
involves the processing of physical goods based on customer input. For the logistics services, processes that are directly related to the product flow the definition of strategic objectives and process objectives should be based on logistic service quality concepts. These projects will be more effective and efficient when customer requirements are known and understood in relation to each other. Because of the focus on customerfocused processes in logistics services, the case organization achieved explicit benefits such as process improvements and flow time reductions due to LSS implementation. The research results show that in logistics services LSS implementation in fact corresponds with improving service quality. One may conclude that, the logistics services sector has potential to benefit from LSS implementation.

This paper furthermore identifies important organizational implementation issues when applying LSS to logistics services. These conclusions may help in further clarifying confusion around Lean implementation as well (Shah and Ward, 2007; Staats et al., 2011). In line with the critical success factors described by Kwak and Anbari (2006), this paper notes the importance of management involvement and organizational commitment to achieve performance improvement. This case study shows that without a well thought out organizational CI structure, efficient and effective process implementation will be difficult to achieve. Furthermore, a lack of training at the beginning of the process may be detrimental to future performance. Strategic analysis, cross-functional teams, improvement tools and process management are important implementation aspects to take into consideration when applying LSS into a logistics services environment.

This case study furthermore shows that the DMAIC approach does not have to be strictly followed in order to reach successful CIPs in a logistics services environment. However, the use of guidelines when working with LSS is helpful. Especially the first steps provided a key contribution to the success of an LSS project. Tools like VSM, SIPOC and process mapping were found useful to visualize the process and to identify what to measure and analyze. However, other prominent improvement tools such as Kaizen, 5S or Kanban (Fullerton et al., 2014; Seth and Gupta, 2005; Vamsi and Sharma, 2014) were not explicitly identified in this case. Another relevant aspect to fit LSS into logistic service environment is to define the VOC, CTQ, objectives and/or deliverables in line with logistics service quality concepts. The case study shows that these concepts 
create the necessary linkages with the business strategy. Moreover, this case shows that during the process implementation the organizational structure as well as training and other resources, were inappropriate. These organizational limitations decreased the probability of successful process improvement. It can be concluded that LSS does not have to follow a formal implementation process. This research shows how some flexibility in aspects such as the number of team members, the phases of the DMAIC process, the usage of tools, or using a trial and error strategy, increases the possibility of obtaining higher benefits from LSS. A customizable LSS implementation is beneficial for its future success.

This research also has significant managerial implications. Firstly, this case study shows how LSS implementation leads to significant improvements in operational aspects of the organization. Furthermore, it shows that some of the improvements can be reached quickly and can already have a considerable impact on performance. Even though the approach is structured and focused on improvements that last in the long term a part of the benefit of LSS is in starting the improvement process. Secondly, the case study highlights the importance of key elements of the organizational implementation process, including top management involvement, organizational infrastructure and crossfunctional teams. Top managers have a complete and strategic perspective of the organization and they can extrapolate solutions and positive experiences to other processes. These aspects are general conditions for a LSS successful implementation. Finally, the detailed description about the DMAIC cycle and its useful tools may offer a guideline for managers who are about to decide on LSS implementation. Nevertheless, managers should consider how to customize LSS implementation to their own organization, and do not follow a formal implementation process strictly following the approach With a strict DMAIC approach an organization may have difficulties in reaching potential LSS benefits.

This study has two main limitations. Firstly, the choice of only one company for the case study limits the generalizability of conclusions drawn. However, given the fact that it is set in the electronics sector, a fast evolving industry, should yet enable other companies to learn from it. Secondly, one of the two CIPs, did not go through a complete DMAIC cycle. Future research may focus on extending the understanding of LSS implementation in specific contexts since there is only a limited amount of 
literature related to LSS implementation in logistics services. Future empirical studies could be focused on large-scale questionnaires to obtain a significant and representative sample size that allow for a better generalization. All these studies will contribute to create a theoretical and empirical background that better help implementing LSS in logistics services environments successfully.

\section{References}

Arnheiter, E.D. and Maleyeff, J. (2005). The integration of Lean management and Six Sigma. The TQM Magazine, Vol.17 No.1, pp.5-18.

Beamon, B.M. and Ware, T.M. (1998). A process quality model for the analysis, improvement and control of supply chain systems. Logistics Information Management, Vol.11 No.2, pp.105-113.

Bhuiyan, N. and Baghel, A. (2005). An overview of continuous improvement: from the past to the present. Management Decision, Vol.43 No.5, pp.761-771.

Braunscheidel, M. J., Hamister, J. W., Suresh, N. C. and Star, H. (2011). An institutional theory perspective on Six Sigma adoption. International Journal of Operations and Production Management, Vol.31 No.4, pp.423-451.

Browning, T. and Heath, R. (2009). Reconceptualizing the effects of lean on production costs with evidence from the F-22 program. Journal of Operations Management, Vol.27, pp.34-44.

Chapman, R.L., Soosay, C. and Kandampully, J. (2003). Innovation in logistics services and the new business model. International Journal of Physical Distribution and Logistics Management, Vol.33 No.7, pp.630-650.

Chen, J.C., Li, Y. and Shady, B.D. (2010). From Value Stream Mapping Toward a Lean/Sigma Continuous Improvement Process: An Industrial Case Study. International Journal of Production Research, Vol.48 No.4, pp.1069-1086.

Cheng, C. and Chang, P. (2012). Implementation of the Lean Six Sigma framework in non-profit organisations: A case study. Total Quality Management and Business Excellence, Vol.23 No.4, pp.431-447. 
Choi, B., Kim, J., Leem, B., Lee, C. and Hong, H. (2012). Empirical analysis of the relationship between Six Sigma management activities and corporate competitiveness. International Journal of Operations \& Production Management, Vol.32 No.5, pp.528550.

CSCMP, (2015). CSCMP Supply Chain Management Definitions. [online] Available at: $<$ http://cscmp.org/aboutcscmp/definitions.asp > [Accessed 5 May 2015].

Davis, F.W. and Manrodt, K.B. (1994). Service Logistics: An introduction. International Journal of Physical Distribution \& Logistics Management, Vol.24 No.4, pp.59-68.

De Leeuw, S. and Fransoo, J. (2009). Drivers of close supply chain collaboration: one size fits all? International Journal of Operations \& Production Management, Vol.29 No.7, pp.720-739.

De Leeuw, S. Gutierrez Gutierrez, L.J. and Dubbers, R. (2013): “An Integrative Model for Lean Six Sigma Implementation in Logistics Services Environments". Review of Business and Economic Literature, Vol.58 No.3, pp.211-230.

Devane, R. (2004). Integrating Lean Six Sigma and High-Performance Organizations: Leading the Charge Toward Dramatic, Rapid and Sustainable Improvement. Pfeiffer, San Francisco, CA.

Eisenhardt, K.M. (1989). Building theory from case study research. Academy of Management Review, Vol.14 No.4, pp.532-550.

Ellram, L.M., Tate, W.L. and Billington, C. (2004). Understanding and managing the services supply chain. Journal of Supply Chain Management, Vol.40 No.4, pp.17-32.

Eroglu, C. and Hofer, C. (2011). Lean, leaner, too lean? The inventory-performance link revisited. Journal of Operations Management, Vol.29, pp.356-369.

Fung, P. and Wong, A. (1998). Case study: managing for total quality of logistics services in the supply chain, Logistics Information Management, Vol.11 No.5, pp.324329. 
Fullerton, R., Kennedy, F., and Widener, S. (2014). Lean manufacturing and firm performance: The incremental contribution of lean management accounting practices. Journal of Operations Management, Vol.32 No.7/8, pp.414-428.

Furlan, A., Vinelli, A., and Giorgia, D.P. (2011). Complementarity and lean manufacturing bundles: An empirical analysis. International Journal of Operations \& Production Management, Vol.31 No.8, pp.835-850.

Furterer, S., and Elshennawy, A.K. (2005). Implementation of TQM and Lean Six Sigma tools in local government: A framework and a case study. Total Quality Management and Business Excellence, Vol.16 No.10, pp.1179-1191.

George, M.L. (2003). Lean Six Sigma for Service. McGraw-Hill, New York, NY.

Gnanaraj, SM, SR Devadasan, R Murugesh, and CG Sreenivasa (2012). Sensitisation of SMEs Towards the Implementation of Lean Six Sigma-an Initialisation in a Cylinder Frames Manufacturing Indian SME. Production Planning and Control, June, pp.37-41.

Green, F. (2006). Six sigma and the revival of TQM. Total Quality Management and Business Excellence, Vol. 17 No. 10, pp. 1281-1286.

Gutierrez, L.J., Tamayo, I., Barrales, V. (2010). Quality management initiatives in Europe: An empirical analysis according to their structural elements. Total Quality Management and Business Excellence, Vol.21 No.6, 577-601.

Gutierrez-Gutierrez, L.J.; Bustinza Sánchez, O.F. and Barrales-Molina, B. (2012). Six Sigma, absorptive capacity and organizational learning orientation". International Journal of Production Research, Vol.50 No.3, pp.661-675.

Heskett, J.L. (1971). Controlling customer logistics service. International Journal of Physical Distribution \& Logistics Management, Vol.1 No.3, pp.141 - 145.

Kwak, Y.H. and Anbari, F.T. (2006). Benefits, obstacles, and future of Six Sigma approach. Technovation, Vol.26, pp.708-715.

Linderman, K., Schroeder, R. G. and Choo, A. S., (2006). Six Sigma: The role of goals in improvement teams. Journal of Operations Management, Vol.24 No.6, pp.779-790. 
Lu, H. and Su, Y. (2002). An approach towards overall supply chain efficiency. Master Thesis, School of Economics and Commercial Law, Göteborg University.

Mentzer, J.T., Flint, D.J. and Hult, T.M. (2001). Logistics Service quality as a SegmentCustomized Process. Journal of Marketing, Vol.65, pp.82-104.

Motwani, J. (2003). A business process change framework for examining lean manufacturing: A case study. Industrial Management \& Data Systems, Vol.103 No.5, pp.339.

Pamfilie, R., Petcu A. and Draghici, M. (2012). The importance of leadership in driving a strategic Lean Six Sigma management. Procedia - Social and Behavioral Sciences, Vol.58, pp.187-196.

Pepper, M.P.J., and Spedding, T.A. (2010). The Evolution of Lean Six Sigma. International Journal of Quality \& Reliability Management, Vol.27 No.2, pp.138-155.

Psychogios, A.G., and Tsironis, L.K. (2012). Towards an integrated framework for Lean Six Sigma application: Lessons from the airline industry. Total Quality Management and Business Excellence, Vol.23 No.4, pp.397-415.

Rahman, S. (2006). Quality management in Logistics: an examination of industry practices. Supply chain Management: An International Journal, Vol.11 No.3, pp.233240.

Salah, S., Rahim, A. and Carretero, J. (2010). The integration of Six Sigma and Lean Management. International Journal of Lean Six Sigma, Vol.1 No.3, pp.249-274.

Schroeder, R.G., Linderman, K., Liedtke, C., Choo, A.S. (2008). Six Sigma: definition and underlying theory. Journal of Operations Management, Vol.26, pp.536-554

Shah, R., and Ward, P.T. (2003). Lean manufacturing: context, practice bundles, and performance. Journal of Operations Management, Vol.21 No.2, pp.129-149.

Shah, R. and Ward, P.T. (2007). Defining and developing measures of lean production. Journal of Operations Management, Vol.25 No.4, pp.785-805.

Snee, R. (2010). Lean Six Sigma - getting better all the time. International Journal of Lean Six Sigma, Vol.1 No.1, pp.9-29. 
Staats, B.R., David J.B., and David M.U. 2011. Lean Principles, Learning, and Knowledge Work: Evidence from a Software Services Provider. Journal of Operations Management, Vol.29 No.5, pp.376-390.

Sunder, V. (2014). Quality excellence in higher education system through Six Sigma: student team engagement model. International Journal of Six Sigma and Competitive Advantage, Vol.8 No.3/4, pp.247.

Sunder, V., and Antony, J. (2015). Six-sigma for improving Top-Box Customer Satisfaction score for a banking call centre. Production Planning and Control, Vol.26 No.6, pp.1291-1305.

Swink, M. and Jacobs, B., W. (2012). Six Sigma adoption: Operations performance impacts and contextual drivers of success. Journal of Operations Management, Vol.30 No.6, pp.437-453.

Vamsi, K.J., and Sharma, A. (2014). Lean manufacturing implementation using value stream mapping as a tool. International Journal of Lean Six Sigma, Vol.5 No.1, pp.89116.

Van den Bos, A., Kemper, B. and de Wall, V. (2014). A study on how to improve the throughput time of Lean Six Sigma projects in a construction company. International Journal of Lean Six Sigma, Vol.5 No.2, pp.212-226.

Voss, C., Tsikriktsis, N. and Frohlich, M. (2002). Case research in operations management. International Journal of Operations \& Production Management, Vol.22 No.2, pp.195-219.

Wang, F.K. and Chen, K.S. (2010). Applying Lean Six Sigma and TRIZ methodology in banking services. Total Quality Management and Business Excellence, Vol.21 No.3, pp.301-315.

Wang, F.K. and Chen, K.S. (2012). Application of Lean Six Sigma to a panel equipment manufacturer. Total Quality Management and Business Excellence, Vol.23 No.3-4, pp.417-429. 